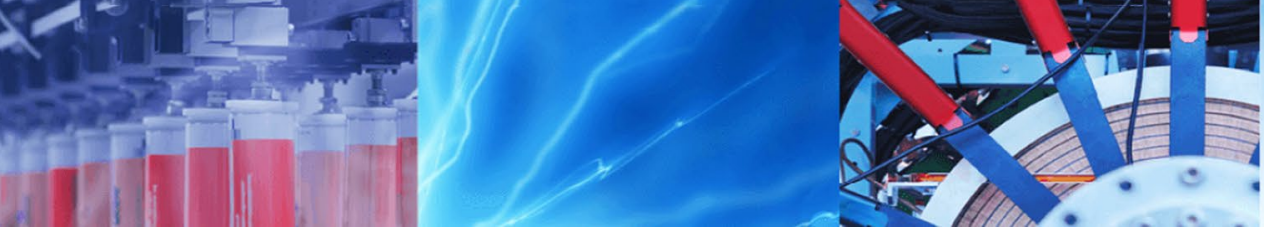

Research Article

\title{
Hydrological modelling in data-scarce catchments: Black Volta basin in West Africa
}

\author{
Stephen Oppong Kwakye ${ }^{1,2}$ ( András Bárdossy ${ }^{2}$
}

Received: 25 September 2019 / Accepted: 7 March 2020 / Published online: 12 March 2020

(c) Springer Nature Switzerland AG 2020

\begin{abstract}
A lumped version of the conceptual HBV-IWS version (Hydrologiska Byrans Vattenbalansavdelning) hydrological model was applied on the Black Volta Catchment in the West African sub-region (a data-scarce catchment) to investigate the performance of the model in the study area. In assessing the robustness of the model and how well it performs in the study area, different optimization methods were used. The Robust Parameter Estimation (ROPE) algorithm was used to generate and calibrate 10,000 best parameter sets in a computer framework with initially set model parameter ranges. The model performed well with an average NS of 0.75 and 0.6 for calibration and validation respectively for subcatchments Lawra and Chache. The performance also improved when a higher weight was given to the low-flows during the optimization. Results also show that the model reacts well to precipitation signals. For a proper management of the water resources and hydropower in the West Africa sub-region and for good policy decisions and investments in water related projects, a robust hydrological model would be essential and crucial for the Black Volta Catchment. The results of this study will be an essential input to a further study in assessing the effects of climate change on the hydrology of the West African sub-region.
\end{abstract}

Keywords Hydrological model · West-Africa $\cdot$ Nash-Sutcliffe-coefficient $\cdot$ Climate change $\cdot$ HBV $\cdot$ Rainfall-runoff model

\section{Introduction}

West Africa is a fast developing sub-region within the African continent with challenges of water availability and variability. Hydropower is the main source of electricity in the sub-region and farming is the major occupation or source of income for the population of the region [50]. Additionally, surface water is also the main source of water supply for the region. The Volta River Authority, the operator of the major hydropower in the sub-region, occasionally has to shut down most of their turbines because of low levels of water in the reservoir and many cities in the region undergo power rationing.

Farmers have lost their planting seeds, crops and harvest because of the delay in the onset of the rainy season and a prolonged dry period [27]. Any changes in the climate, the hydrology and the water resources of the region tremendously affect both the people and the economy of the sub-region as a whole.

The Black Volta basin is shared by four countries in the region namely Mali, Burkina Faso, Ghana and Ivory Coast. This obviously results in an increasing competing demand of the scarce water resources. Therefore, a model to simulate the hydrology of this basin would be beneficial to not only one country but several others in the sub-region.

Countries in the region are in the lower to middle income economies and have very scarce meteorological and hydrological data [54]. Because of that, a simple but scientifically proven hydrological model, which is not too

Stephen Oppong Kwakye, oppongsteven@yahoo.com | ${ }^{1}$ Civil Engineering Department, Kumasi Technical University, Kumasi, Ghana. ${ }^{2}$ Institute for Modelling Hydraulic and Environmental Systems, University of Stuttgart, Stuttgart, Germany. 
data demanding, would be a useful tool for the management of water resources and hydropower.

Several studies have revealed that climate change has already made an impact in the sub-region (e.g. [25-28, $30,31,34,38,39$ ] and an established hydrological model could be used in further studies to assess the effects of climate change on the water resources. A better understanding of the hydrological regime of the sub-region would be very instrumental in helping policy makers and water resource managers to make important decisions on investment, development and management.

According to Beven [12], the types of hydrological models range from the empirical (e.g. Regression models) to the conceptual (e.g. HBV, HYMOD) and physically based models (e.g. TOPMODEL, MIKE SHE). Empirical models are purely based on analyzing observed input and output data (e.g. rainfall, discharge). Their advantages are that they are simple in structure and parameter estimation and include empirical knowledge. A conceptual model has a conceptual description of important processes and the model variables and parameters have an abstract meaning. It has the advantages of a simple processes description, a good performance especially at large scales and low amount of input data and number of parameters. A physically based model has its process description based on first principles and its parameters and state variables may be directly measured in the field. It has the merits of an advanced process description and good performance especially at small scales.

In selecting the appropriate hydrological model for this study, the following criteria were considered:

- Because of the large size of the catchment and the coarse network of available data for the catchment, the chosen model should not be complex and data intensive. The requirement of data should be met by the available observations and measurements within the study area.

- There should not be too many parameters in the model structure.

- The structure of the model should describe and represent the most important runoff generating processes in a scientifically reasonable way.

From the literature gathered, it was revealed that some studies have already been done on the application of hydrological models in the sub-region. For example, Niel et al. [37] applied a lumped hydrological model to 17 west and central African catchments to study parameter stability related to climate change studies. Their study revealed that non-stationarity in rainfall or runoff series does not imply non-stability of the model parameters. Andersen et al. [3] successfully applied and validated the physically-based-distributed MIKE SHE model to the large Senegal River basin. Moreover, a study performed by Paturel et al. [40] using a semi-distributed empirical model showed reasonable results for rainfall-runoff modeling for different West African catchments. The results of Dezetter et al. [15] demonstrated that the choice of soil datasets shows the highest sensitivity of the model, but no single data-model combination yielded the best results for all catchments under consideration. In their study, they used 49 West African catchments to investigate the effects of using different hydrological modeling approaches and input grids on the simulation of runoff. A good performance of monthly streamflow prediction was demonstrated by Amisigo et al. [1], when they used a statistical model (NARMAX) for several subcatchments of the Volta basin. Jung [26] used a joint dynamical downscalinghydrological model for climate impact studies for the Black Volta basin in this region.

Wagner [54] used the joint meteorological model (MM5) and WaSiM in his research for hydrological simulations in the White Volta basin in West Africa and the results showed a good performance for discharge in the year 2004 and a weaker one for 2005 due to precipitation overestimations. The results also showed that the performances of the hydrological simulations using the scaled TRMM 3B42 product were good with an average NS of 0.6 for the discharge year 2004. He also concluded that using station data as meteorological data source led to good and often best model efficiencies. Shaibu et al. [47] used a simplified runoff model for the Black Volta basin using an adjusted monthly TRMM 3B42 product as input data and the results were encouraging ( $N S=0.89$ ).

The conceptual HBV hydrological model has only been applied in a West Africa catchment by Götzinger [20], although the physically based hydrological model WaSIM had been extensively applied in the sub-region $[26,28$, $29,54]$. In the study of Götzinger [20], the modified distributed HBV was applied in the Oueme basin in Benin (West Africa), which is on the same climate domain as the Black Volta basin. The results were that the total simulated discharge matches the scale and variability of the observations sufficiently well for water resources management planning and that, the general seasonal behavior but not all observed flood peaks could be reproduced. At the outlet of the catchment, at gauge Bonou ( 51,543 square kilometers) the Nash-Sutcliffe model efficiency for daily discharge was 0.77 for calibration. The average Nash-Sutcliffe coefficient of all sub-basins in the Oueme catchment for the validation period was 0.50 [20]. The water balance of the whole Oueme catchment could be reproduced with satisfactory accuracy considering the available data and their uncertainties. He revealed further in the Oueme basin that the model efficiencies themselves are acceptable but 
the variability of the discharge was not modelled well from an operational perspective. The model was not able to simulate all additional short-term fluctuations and the full extent of the dry season. This is one of the shortcomings that our research tried to overcome by looking at how well the hydrological model reacts to precipitation signals or changes (i.e. how the model performs after there is a change in the precipitation amounts and time scales) and how stable the model might be by employing various techniques and methods for calibration and validation. Götzinger [20] suggested that the modified HBV model was suitable for global change impact studies.

The HBV model [8] was therefore considered suitable for this study and was set up, calibrated and validated for two different time spans and sub-catchment sizes. The model is not data intensive which makes it ideal for the study area being a data scarce environment. The novelty in this study is the use of different or various optimisation methods and model performance measures for both calibration and validation, in order to assess the robustness and stability of the model in the study area. From the review of literature, it was realised that most hydrological models performed globally and locally in the sub-region more often used only one performance measure (mostly Nash-Sutcliffe (NS)) to assess the performance of the model, for example $[3,20,47,54]$. We believe that it is not good enough to only conclude on the efficacy of hydrological models just on the NS measure. In this study, we vigorously tested our model by using different performance measures and different calibration/validation techniques and input data to assess how well the model performed under different circumstances.

The authors wish to state that this paper is born out of the dissertation of the first author and as such, there could be overlap between the dissertation which could be accessed at elib.uni-stuttgart.de and this journal article.

\section{Study area and data sources}

The study area is the Black Volta basin in Western Africa and has a total catchment area of about $155,000 \mathrm{~km}^{2}$ (Fig. 1) and is shared by four West African countries (Ghana, Mali, Burkina Faso and Ivory Coast). The Black Volta River is the main river in the catchment which empties into the Volta Lake (which is one of the largest artificial lakes in the world). The Black Volta basin is about one-third of the entire Volta basin, which comprises the White, Black and Lower Voltas and the Oti subcatchment. The major water resources usage in the catchment area includes hydropower, small scale irrigation and domestic water supply. The catchment lies in a data scarce environment. The main tributaries of the Black Volta river are Bougouriba,
Gbongbo, Grand Bale, Voun Hou, Sourou, Wenare, Bambassou, Bondami, Tain and Poni rivers [35, 56].

The basin can be found approximately between latitudes $7^{\circ} \mathrm{N}$ to $15^{\circ} \mathrm{N}$ and $5^{\circ} 30^{\prime \prime} \mathrm{W}$ to $1^{\circ} \mathrm{W}$. According to Shahin [46], the Black Volta River used to join the White Volta River at the south-eastern part of Ghana but after the creation of the Volta Dam, the Black and White Voltas do not join each other anymore, instead each river enters the lake through a separate channel. The head water source of the Black Volta is in the Banfora Cliffs in Burkina Faso. The river then traverses on the left bank side of the Sourou (a north-south depression). Below the depression, the flow of the river is generally in a southerly direction with a number of meanders in its course [46].

In knowing the terrain of the study area, a 30 arc second (approximately $1 \mathrm{~km}$ at the equator) digital elevation map (DEM) for the African continent was obtained from the USGS earth explorer database. Once again, the area of interest which is the Black Volta basin was clipped using ArcGIS with the help of a shape file of the catchment. From the DEM map (Fig. 2), the elevation ranges from 82 to $887 \mathrm{~m}$ above sea level with the higher elevations around the western part of the catchment. The northern part of the catchment is almost flat with low elevations and slopes towards the central part where the Black Volta River is located. There is considerable variation in local relief of the basin. The northern areas range between 300 and $700 \mathrm{~m}$ above sea level and the southern sector are covered with water bodies or with height ranging from 0 to $150 \mathrm{~m}$ above sea level. The basin is gently undulating from the north to the south.

Since the $1960 \mathrm{~s}$, tropical West Africa has suffered from declining rainfall and several drought periods that occurred in the early 1970s and in the first half of the 1980s [50].

Meteorological and hydrological data sets were obtained from the Volta basin Geoportal, which can now be accessed at (https://data.zef.de/geonetwork_zef/apps/ search/), meteorological agencies of both Ghana and Burkina Faso and from the Hydrological Services Department of Ghana. A total of 20 observed precipitation stations in and around the study area were used for the analysis (Fig. 1). The duration of these time series is from 1961 to 2005 (45 years) with a daily temporal resolution. Some of the gauge stations are located in Ghana and the rest in Burkina Faso and Ivory Coast (Fig. 1). The names of the stations are Bechem, Sunyani, Berekum, Wenchi, Kintampo, Bui, Bole, Batie, Gaoua, Babile, Lawra, Baguera, Banfora Agri, Bob-Dioulasso, Diebougou, Dano, Boura, Boromo, Bagassi and Bomborokuy.

The mean daily rainfall values were calculated for a 45 year period for each station. Then a 10-day movingweighting function was applied to smoothen the daily 

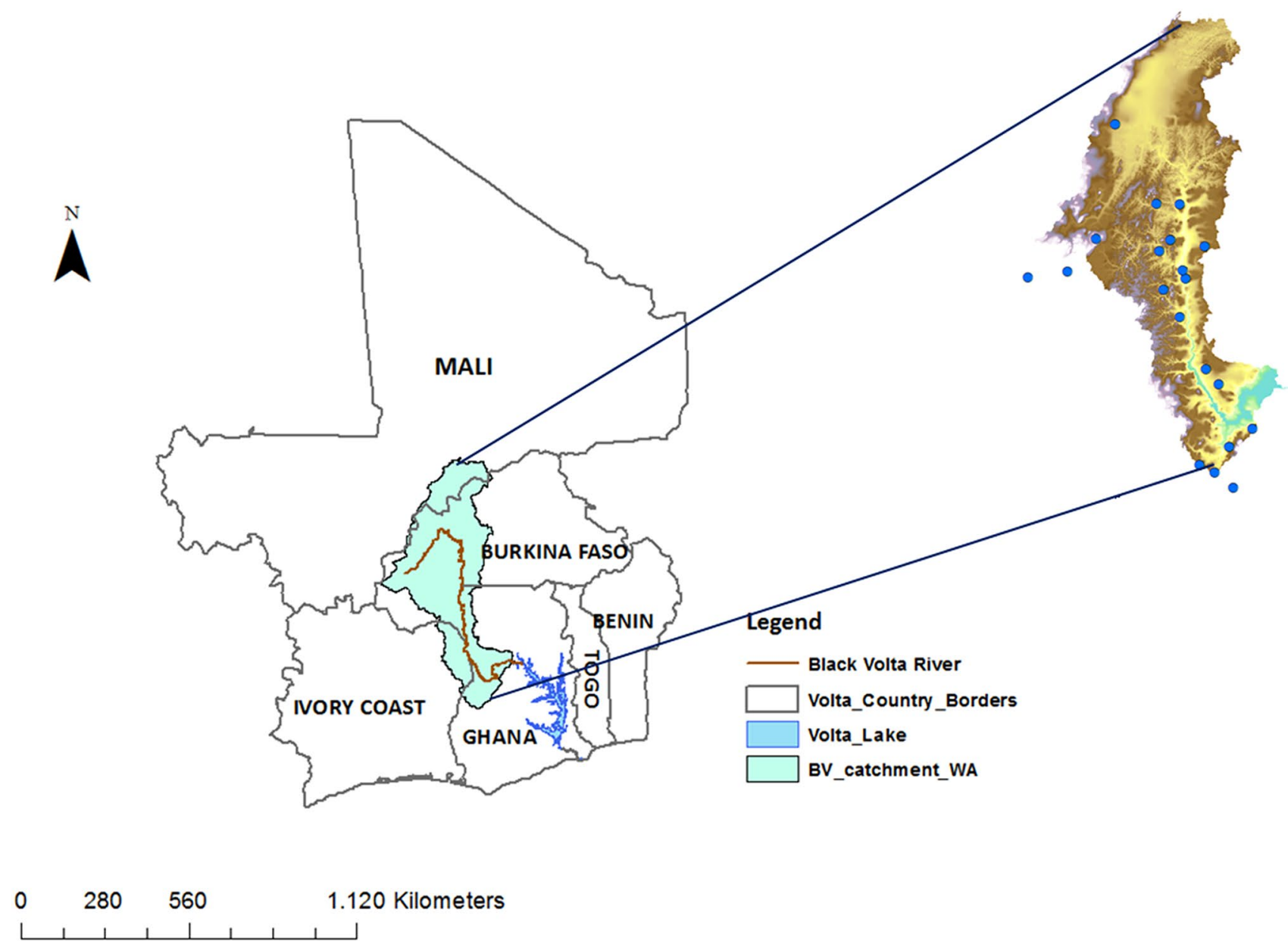

Fig. 1 The Black Volta basin with its riparian countries (Insert: Black Volta basin showing digital elevation map and the rainfall gauge stations)

rainfall values and to remove the noises in the data. We could then have an annual cycle of rainfall for each gauge station.

From the results, there was a clear bi-modal rainfall cycle in the south of the catchment with rainfall seasons from April to July, September to October and a uni-modal cycle in the north of the catchment with rainfall season from June to September. There is a negative gradient in rainfall as one moves from the south to the north of the catchment. For a station in the north, the month of August has the highest amount of rainfall while January is the driest month in the year. A station in the south has the first rainfall season peaking in May/ June while the second season peaks in September/October and the driest month is January (Fig. 3). The average daily rainfall was $9 \mathrm{~mm} /$ day for a station in the north and $7 \mathrm{~mm} /$ day for a station in the south. In the northern part of the sub-region, one could get on the average only 4 months of rain in a year while there is about six to 7 months of rain in a year in the southern part. Probably, this could explain why there are more farming activities in the southern part of the catchment as compared to the north, since farming in these areas are rain-fed.

There are 11 temperature stations and 2 stream flow gauges (Lawra and Chache; Fig. 4) with a daily resolution data for the same period as the rainfall data.

The discharge data were briefly quality checked by calculating the Runoff Coefficient (RC) as the ratio of the river discharge, $Q$, to the precipitation, P. It was revealed that the RC for the Black Volta basin is approximately $3.4 \%$ which is similar to what Jung [26] obtained in her study. The research work conducted by Taylor et al. [51] on the Volta basin discharge data quality assessment showed that there is a high correlation $(r>0.94)$ among the discharge data at several gauge stations within the catchment. A comparison of streamflow data sources from different riparian countries within the catchment repeated a high correlation. However, there are many missing data gaps in most of the discharge data, and we 


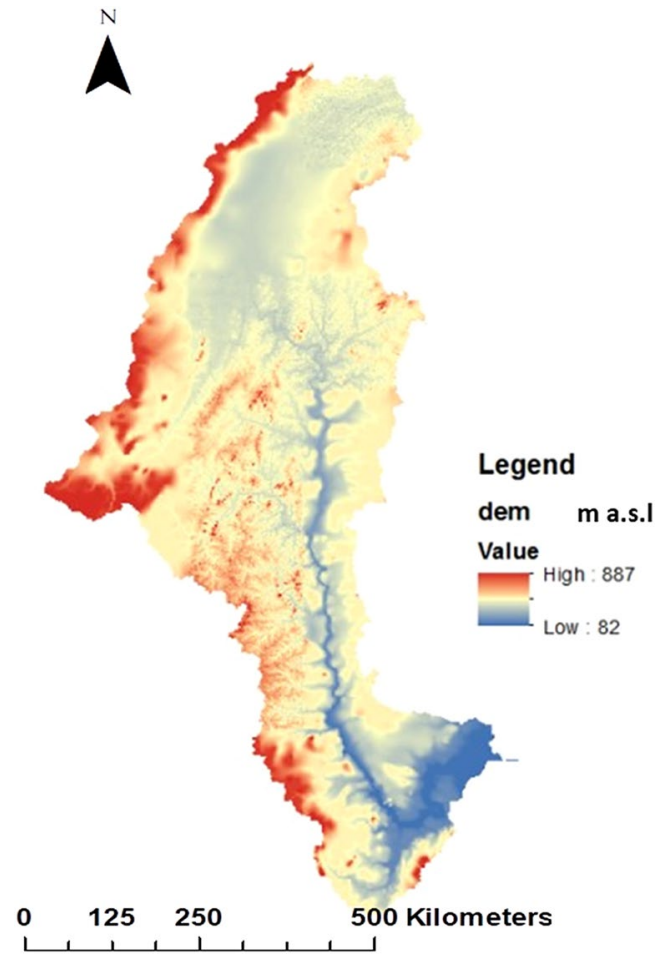

Fig. 2 Digital elevation map of the Black Volta basin

were restricted to the discharge data that could be used to calibrate and validate the hydrological model.

We did not perform any gap filling of the data because we wanted to use the original measured data for our studies, although we are much aware of methods and previous studies of gap-in-filling $[2,4,14,48]$. Most of those methods use statistical approaches which are not $100 \%$ reliable and might not have a significant effect on the results of our model and the overall results of our study.
The precipitation $(P)$ and temperature $(T)$ measured data that we used for our studies is an areal precipitation calculated using arithmetic mean method which automatically averages out and as such, the input precipitation and temperature for our model is not affected by any gap in the station data. The measured discharge $(\mathrm{Q})$ data that was used to calibrate and validate our model was chosen such that there were minimal gaps (averagely $4 \%$ ) in it by selecting the time series with very few gaps.

\section{Methodology}

\subsection{HBV-hydrological model}

The model was originally developed at the Swedish Meteorological and Hydrological Institute (SMHI) and was first applied in the early 1970s [9]. There have been some modifications to the model over time, but the philosophy behind the model has been unchanged [32]. This model has been extensively applied in Europe and other parts of the world $[7,13,16,21,23,32,42,57]$. Götzinger [20] also applied it in the Oueme basin in Benin (West Africa). Slight modifications have been made to the original model by the Institute for Modelling Hydraulic and Environmental Systems (University of Stuttgart) and it is referred to as HBV-IWS model. In this study, the lumped version of the HBV-IWS model was used. The model consists essentially of four parts:

- Snow accumulation and melt

- Soil moisture and runoff generation

- Runoff concentration within the subcatchment and

- Flood routing in the river network
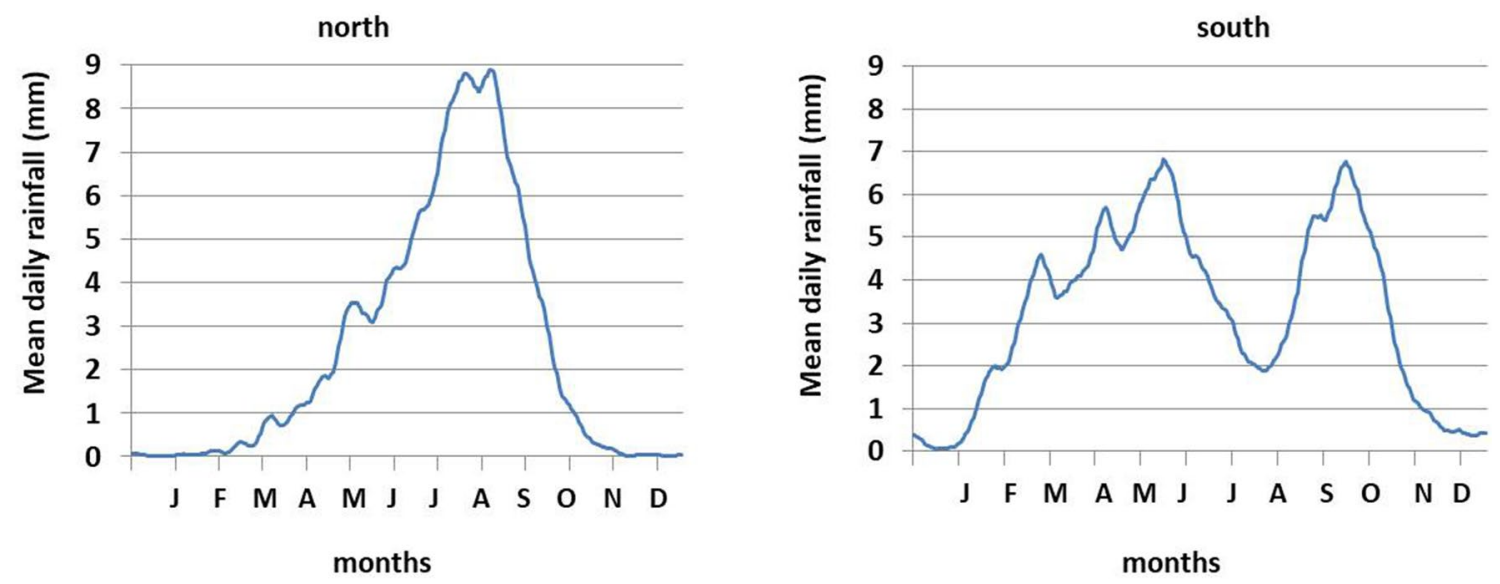

Fig. 3 Left: annual rainfall cycle for a typical station in the north. Right: annual rainfall cycle for a typical station in the south of the study area 


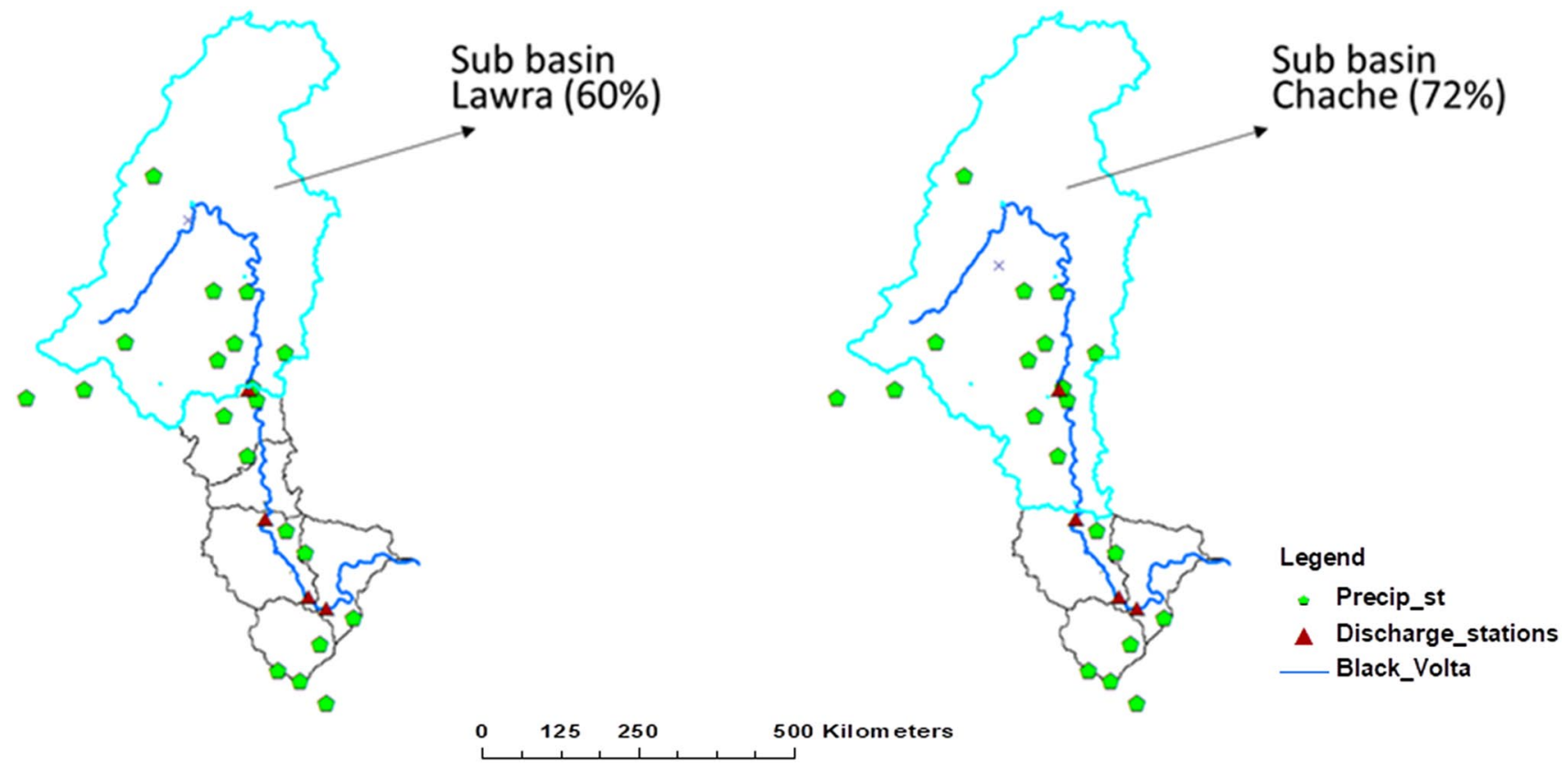

Fig. 4 The two sub basins (Lawra and Chache) used for the study with their representative part (\%) of each of them on the whole basin. (Green pentagons represent the meteorological and the red triangles show the discharge stations)

Because the study area is in the tropics, there is no precipitation as snow therefore the snow accumulation and melt module in the model was taken out.

\subsubsection{Soil moisture accounting}

The soil moisture accounting routine calculates the proportion of rainfall that reaches the soil surface that produces runoff. This is related to the soil moisture deficit and is calculated as:

$\Delta Q / \Delta P=(S M / F C)^{\beta}$

where $\Delta Q$ is the contribution of the zone to runoff [mm], $\Delta P$ rainfall or snowmelt [mm], $S M$ actual soil moisture $[\mathrm{mm}], F C$ maximum storage capacity of the soil $[\mathrm{mm}], \beta$ a model parameter.

The remaining part of the rainfall is added to the soil moisture until the storage capacity of the soil (FC) is reached.

\subsubsection{Evapotranspiration}

The evapotranspiration in each month is computed by using the long term mean monthly evapotranspiration. The daily mean air temperature is used to adjust the daily values of potential evapotranspiration according to the relation:

SN Applied Sciences
$P E_{A}=\left(1+C_{E T}\left(T-T_{M}\right)\right) P E_{M}$

where $P E_{A}$ adjusted potential evapotranspiration [mm/ day], $P E_{M}[\mathrm{~mm} /$ day] long term mean evapotranspiration for a given month, TM long term mean monthly air temperature $\left[{ }^{\circ} \mathrm{C}\right], T$ mean daily air temperature $\left[{ }^{\circ} \mathrm{C}\right], C E T$ model parameter $\left[{ }^{\circ} \mathrm{C}^{-1}\right]$, The actual evapotranspiration is calculated as:

$E_{A}= \begin{cases}P E_{A} & \text { if } \frac{S M}{C M A X} \geq \eta \\ \min \left(\frac{S M}{\eta \cdot C M A X} P E_{A}, S M\right) & \text { else }\end{cases}$

where $E_{A}$ actual evapotranspiration from the soil zone [mm/day], $P E_{A}$ potential evapotranspiration from the soil zone, $S M$ actual soil moisture [mm], CMAX place [mm] limiting soil moisture at which actual evapotranspiration takes, $\eta$ water balance parameter.

The relationship between potential and actual evapotranspiration can differ strongly due to water or energy limitations. Therefore, the parameter $\eta$ is introduced to control the ratio between daily potential and actual evapotranspiration depending on the available water and depends on the long term water balance only. If there is enough water, then all the potential evapotranspiration is evaporated as actual, else the potential evapotranspiration is reduced by the factor $\left(\frac{S M}{\eta \cdot C M A X}\right)[6]$. 


\subsubsection{Runoff response process}

The runoff response function is used to transform the runoff computed in the soil moisture accounting to discharge at the outlet of the catchment. It controls the time distribution of the generated runoff. The runoff response routine comprises two conceptual reservoirs cascaded over one another. The upper reservoir consists of two outlets which are used to conceptualize the direct runoff component from the upper soil zone and the inter-flow. Soil water is percolated to the lower (second) reservoir. The lower reservoir is linear and the output represents the base flow component of the runoff. The response function is governed by three recession coefficients $\left(K_{0}, K_{1}\right.$ and $K_{2}$ ), one percolation capacity (PERC), one threshold water level $\left(L_{1}\right)$ and one parameter in the transformation function (MAXBAS): altogether six empirical parameters [24, 49]. The upper reservoir is fed by the excess water from the soil moisture accounting routine and the flows at time step $\mathrm{t}$ from its two outlets are given by:

$Q_{0}\left(t_{i}\right)=K_{0}\left(S_{1}-L_{1}\right)$

$Q_{1}\left(t_{i}\right)=K_{1} S_{1}$

where $Q_{0}\left(t_{i}\right)$ is the outflow from the near surface of the upper reservoir $\left[\mathrm{mm} /\right.$ day], $Q_{1}\left(t_{j}\right)$ is outflow from the bottom outlet of the upper reservoir [mm/day], $K_{0}, K_{1}$ is recession coefficients of the near surface and inter flows respectively $\left[\right.$ day $\left.^{-1}\right], S_{1}$ is effective depth of water in the upper reservoir [mm] and $L_{1}$ is the threshold water level for near surface flow [mm].

The lower reservoir is fed by a percolation rate controlled by a parameter PERC from the upper reservoir. The outflow from the lower reservoir at time step $t_{i}$ is calculated as:
$Q_{2}\left(t_{i}\right)=K_{2} S_{2}$

where $Q_{2}\left(t_{i}\right)$ is the outflow from the lower reservoir [mm/ day], $K_{2}$ is the recession coefficients of the lower reservoir $\left[\right.$ day $^{-1}$ ] and $S_{2}$ is the depth of water in the lower reservoir [mm].

The total runoff $Q_{g}$ is computed as the sum of the outflows from the upper and the lower reservoirs as:

$Q_{g}\left(t_{i}\right)=Q_{0}\left(t_{i}\right)+Q_{1}\left(t_{i}\right)+Q_{2}\left(t_{i}\right)$

where $Q_{g}\left(t_{j}\right)$ total generated runoff at the outlet of a catchment [mm/day].

A triangular transformation function whose base is defined by a parameter MAXBAS [days] as shown in Fig. 5 is used to smooth the total runoff.

$Q\left(t_{i}\right)=\sum_{j=0}^{T} \tau(j) Q_{g}\left(t_{i-j}\right)$

where $Q\left(t_{i}\right)$ is the final transformed total runoff at the outlet of the catchment [mm/day], $\tau(j)$ is the weighting function at step jth time step and $T$ is MAXBAS expressed as an integer multiple of the time-step used for runoff computation.

Figure 6 shows a schematic representation of the HBVIWS version. There are 9 parameters to describe the model but because the snow accumulation and melt routine are taken out; it is left with 7 parameters which are used for calibration in this research (Table 1). Table 1 also shows the model parameter range used in the HBV model.

\subsection{Model performance measures}

The performance of the model was determined by comparing simulated discharge $(\mathrm{Q})$ with observations. The
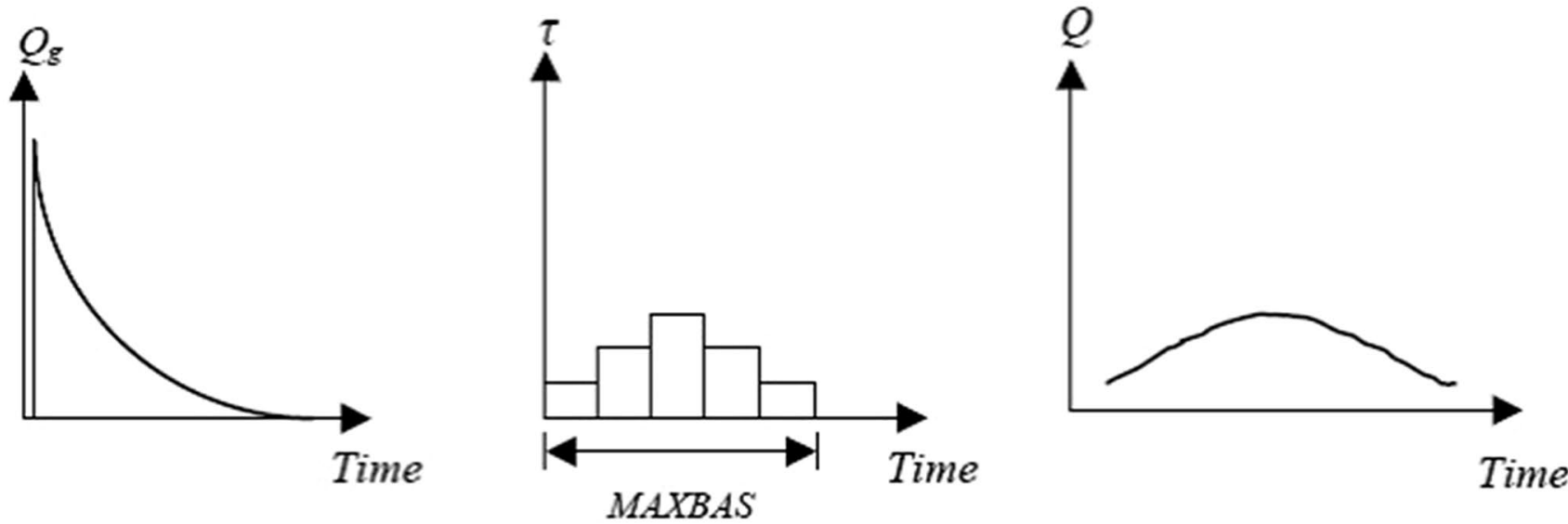

Fig. 5 Smoothing of the generated runoff Qg to obtain Q (source: [24]) 


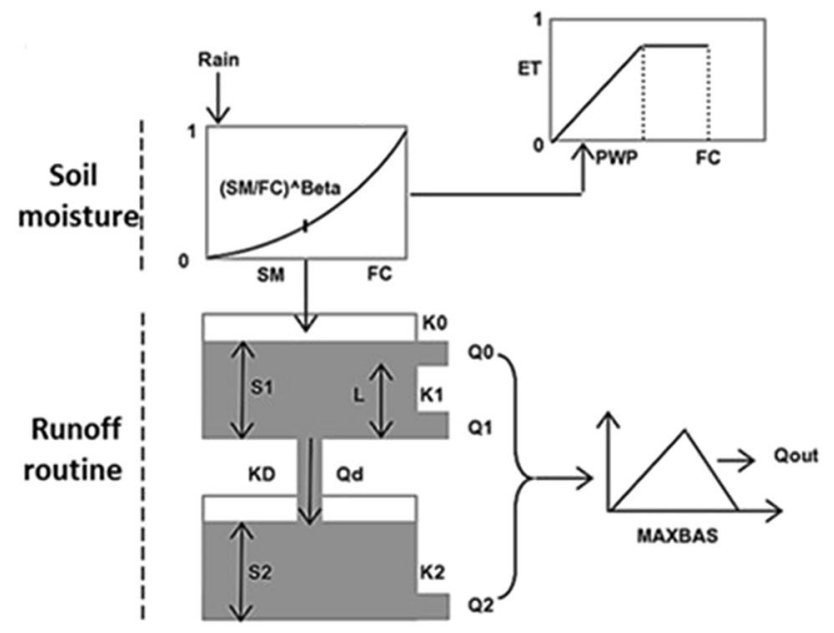

Fig. 6 Schematic representation of HBV-IWS model which is slightly modified for the study area. Adapted from Hundecha and Bardossy [24]

Table 1 Model parameter range for HBV model. Source: [5]; max. and min. values were slightly modified for the study area

\begin{tabular}{llll}
\hline Parameter & Description & Max & Min \\
\hline FC & Field capacity $(\mathrm{mm})$ & 600 & 50 \\
BETA & Shape coefficient & 8 & 0.2 \\
K0 & Near surface flow storage constant & 0.8 & 0.02 \\
K1 & Interflow storage constant & 0.25 & 0.01 \\
K2 & Baseflow storage constant & 0.1 & 0.001 \\
KD & Percolation storage constant & 0.2 & 0.005 \\
L1 & Threshold water level for near sur- & 100 & 1 \\
& face flow (mm) & & \\
\hline
\end{tabular}

following different criteria were used to assess the performance of the model.

The popular and frequently used, Nash-Sutcliffe coefficient (NS) (Eq. 9) [36]. The NS is a normalized measure (-inf to 1.0) that compares the mean square error generated by a particular model simulation to the variance of the target output. It compares the performance of the particular model to that of the one that uses the (constant) mean value of the observed target as its prediction. NS value $=1.0$ shows perfect model performance, an NS $=0$ indicates that the model is, on average, performing only as good as using the mean target value as prediction, and an NS value $<0.0$ indicates a questionable choice of model. Modellers therefore prefer NS values to be larger than 0.0 and approaching 1.0 [45].

In focussing on low flow conditions in the catchment, the Nash-Sutcliffe coefficient of the logarithm of the discharge (LogNS) (Eq. 10) was also used. To equally concentrate on high and low flows, a combination of NS and LogNS was used as one of the performance measures.

The Nash-Sutcliffe with a Bias constraint (NS-Bias) (Eq. 11) as proposed by Viney et al. [53] was also used.

The equations below represent functions of the various performance measures used in the study. Best possible value for all the performance criteria is unity.

$$
\begin{aligned}
& N S=1-\frac{\sum_{t=1}^{T}\left(Q_{o b s}(t)-Q_{\text {sim }}(t)\right)^{2}}{\sum_{t=1}^{T}\left(Q_{o b s}(t)-\bar{Q}\right)^{2}} \\
& \log N S=1-\frac{\sum_{t=1}^{T}\left(\ln Q_{o b s}(t)-\ln Q_{s i m}(t)\right)^{2}}{\sum_{t=1}^{T}\left(\ln Q_{o b s}(t)-\ln \bar{Q}\right)^{2}} \\
& N S_{\text {Bias }}=N S-5 \mid\left.\ln (1+\text { Bias })\right|^{2.5}
\end{aligned}
$$

where the Bias is calculated as:

Bias $=\frac{\sum_{t=1}^{T} Q_{\text {sim }}(t)-\sum_{t=1}^{T} Q_{o b s}(t)}{\sum_{t=1}^{T} Q_{o b s}(t)}$

where $Q_{o b s}(t)$ and $Q_{\text {sim }}(t)$ represent the observed and simulated discharges at times $(\mathrm{t})$ respectively and $\bar{Q}$ is the mean of the observed discharge. In is the natural logarithm.

According to Bárdossy et al. [6], the NS model performance criterion was often criticized (for example, in [45], and several modifications and other criteria were suggested. Therefore, Gupta et al. [22] have published one interesting performance measure which accounts for the water balances and the correlation of the observed and modeled time series separately. Their approach was slightly modified by Bárdossy et al. [6] and it is used in this study:

$G K=1-\beta\left(\frac{\sum_{t=1}^{T}\left(Q_{o b s}(t)-Q_{s i m}(t)\right)}{\sum_{t=1}^{T} Q_{o b s}(t)}\right)^{2}-\left(1-r\left(Q_{o b s}, Q_{s i m}\right)\right)^{2}$

where $r\left(Q_{o b s}, Q_{\text {sim }}\right)$ is the Pearson correlation coefficient between the observed and simulated time series of discharge. $\beta$ is a weight to express the importance of the water balance. In our study, $\beta=5$ was selected. According to Bárdossy et al. [6], the reason for selecting this version of the coefficient is that a model should produce good water balances and appropriate discharge dynamics simultaneously and the quadratic form in Eq. 13 assures that both aspects are considered and the worse of them is dominant. The abbreviation GK is used subsequently for this performance measure. The best possible value for this metric is unity. 
Overall, a model is said to be good when: (1) It reproduces streamflow observations and (2) It reacts to signals in an appropriate manner by being able to simulate or react to changes in the rainfall signals or input data. Some researchers only use the first point in assessing how well a model performs without considering the second important point of the model reacting to signals in an appropriate manner. In this study, we went further to ascertain how well the model performs and its reaction to rainfall input signals, by introducing the following optimisation or calibration techniques:

1. Different objective functions were used for model calibration and validation. (e.g. NS, LogNS, an approach based on Kling Gupta (GK), NS with a bias constraint, a combination of NS and LogNS and Correlation)

2. Using different sub-catchments

3. Calibrating on daily temporal scale and checking performance on different scales (i.e. daily, monthly and residuals: annual cycle subtracted from the specific variable)

4. Calibration on different temporal scales (i.e. daily, monthly, residuals)

5. Swapping of data for calibration and validation

6. Calibrating on dry periods and validating on wet periods and vice versa

\subsection{Robust parameter estimation (ROPE)}

The robust parameter estimation (ROPE) algorithm is an automatic calibration algorithm which generates best parameter sets based on a data depth function [5]. Depth functions were first introduced by Tukey [52] to identify the center (a kind of generalized median) of a multivariate dataset. Several generalizations of this concept have been defined by Rousseeuw and Struyf [44], Liu and Yao [33] and Zuo and Serfling [58]. According to Bardossy and Singh [5], these parameter sets are in the interior of the data depth and are themselves good, transferable and not very sensitive (i.e. small changes of the parameters should not lead to very different results).

The following procedure is used for modeling purposes in finding the set of good parameters and also the identification of the deep (good) parameter vectors for robust modeling:

1. The ranges for the $d$ selected parameters are identified. In this study the range was adopted from the study of Bardossy and Singh [5] and was slightly modified to suit the study area (Table 1).

2. $\mathrm{N}$ random parameter vectors forming the set $X_{N}$ are generated in the $d$ dimensional rectangle bounded by the limits defined in (1)
3. The model performances are calculated after the hydrological model is run for each parameter vector in $X_{N}$

4. The subset of the best performing parameters is identified. This might be for example the best $10 \%$ of $X_{N}$

5. $M$ random parameter sets forming the set $Y_{M}$ are generated, such that for each parameter vector $\theta \in Y_{M}$, the depth function $D(\theta) \geq L$ (with $L \geq 1$ ) is calculated with respect to the set and $L$ is the chosen limit.

6. The set $Y_{M}$ is relabeled as $X_{N}$ and steps 3-6 are repeated until the performance corresponding to $X_{N}$ and $Y_{M}$ does not differ much or until the pre-determined number of iterations is over.

Figure 7 further illustrates the procedure described above. Additional information about the ROPE algorithm can be found in Bardossy and Singh [5]. In this study, 10,000 best parameter sets was generated and calibrated in a computer framework using ROPE with the initially set model parameter ranges. The 90th quantile of the band of simulated discharges for 10,000 best parameter sets are analyzed and discussed in the subsequent section.

\section{Results and discussions}

\subsection{Performance measures for different sub-catchments}

Tables 2 and 3 summarize the results of the model performance for two separate sub-catchments (Lawra and Chache) all located in the study area. Considering the availability of observed discharge, for subcatchment Lawra, the period used for calibration was 1992-1996 while 1997-2001 was used for the validation period. For the subcatchment Chache, the periods 1996-2000 and 2001-2005 were used as calibration and validation periods respectively. In both cases, the first year was used as a warm-up period for the model.

The model performs quite well using NS as the objective function with a mean value of 0.75 and 0.57 for calibration and validation respectively for station Lawra (Table 2). There was a slight increase in the model performance for station Chache with a mean value of 0.79 for calibration and 0.6 for validation using NS as the objective function (Table 3). The big drop in model performance from calibration to validation, suggests some over-fitting going on in the model. By nature, models are imperfect representations of the real world and thus model uncertainties will be always present [18]. Inherent complexities of natural mechanisms, as well as inappropriate assumptions within the entire modelling procedure give rise to these uncertainties. To be precise, uncertainty is related to the 
Fig. 7 Schematic representation of the data depth function and robust parameter estimation algorithm according to Bardossy and Singh [5]
Table 2 Model performance for sub-catchment Lawra (size: 92,877 km2) using daily time scale for calibration and validation
Table 3 Model performance for sub-catchment Chache (size: 111,258 km2) using daily time scale for calibration and validation

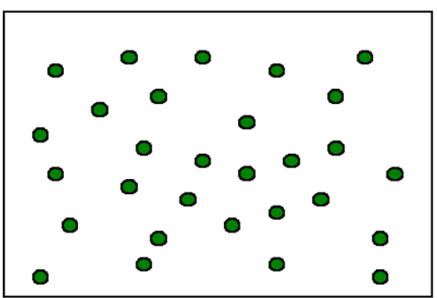

a Generate random parameter sets $X_{N}$, run the model

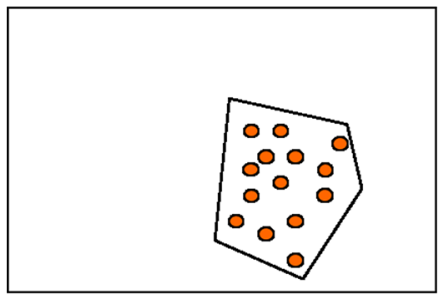

c Generate random parameter sets $Y_{M}$ according to the good subset $X^{\prime}{ }_{N}$ based on the depth function ( $D>=1$ )

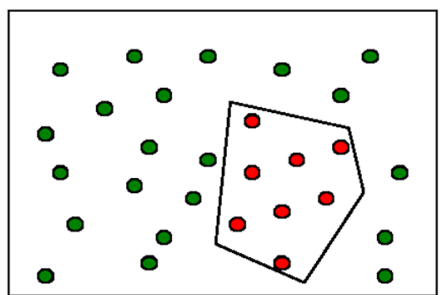

b Identify the good subset $X_{N}^{\prime}$

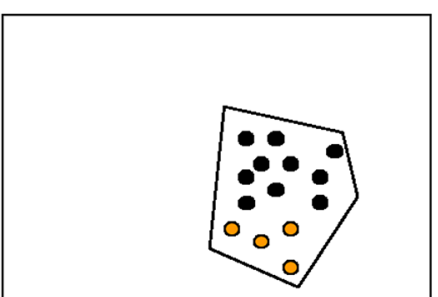

d Identify the good subset $X^{\prime}{ }_{N}$, and repeat from $\mathrm{c}$

\begin{tabular}{|c|c|c|c|c|c|c|}
\hline \multirow[t]{2}{*}{ Performance measure } & \multicolumn{3}{|c|}{ Calibration } & \multicolumn{3}{|c|}{ Validation } \\
\hline & Min & Max & Mean & Min & Max & Mean \\
\hline NS-Bias & 0.71 & 0.82 & 0.75 & 0.16 & 0.73 & 0.5 \\
\hline NS & 0.71 & 0.82 & 0.75 & 0.22 & 0.73 & 0.57 \\
\hline LogNS & 0.51 & 0.66 & 0.59 & - & - & - \\
\hline$(N S+\log N S) / 2$ & 0.58 & 0.69 & 0.63 & 0.42 & 0.59 & 0.49 \\
\hline$(N S+3 \log N S) / 4$ & 0.61 & 0.72 & 0.67 & 0.4 & 0.59 & 0.5 \\
\hline Correlation & 0.85 & 0.92 & 0.87 & 0.81 & 0.91 & 0.85 \\
\hline GK & 0.98 & 0.99 & 0.98 & 0.96 & 0.99 & 0.98 \\
\hline
\end{tabular}

\begin{tabular}{llllllll}
\hline Performance measure & \multicolumn{2}{l}{ Calibration } & & & \multicolumn{2}{l}{ Validation } \\
\cline { 2 - 3 } & Min & Max & Mean & & Min & Max & Mean \\
\hline NS-Bias & 0.69 & 0.88 & 0.8 & & 0.49 & 0.73 & 0.6 \\
NS & 0.68 & 0.88 & 0.79 & & 0.47 & 0.74 & 0.6 \\
LogNS & 0.69 & 0.84 & 0.77 & & 0.57 & 0.78 & 0.65 \\
(NS+LogNS)/2 & 0.7 & 0.83 & 0.77 & & 0.53 & 0.71 & 0.61 \\
(NS+3LogNS)/4 & 0.75 & 0.82 & 0.79 & & 0.6 & 0.69 & 0.64 \\
Correlation & 0.86 & 0.94 & 0.91 & & 0.75 & 0.88 & 0.83 \\
GK & 0.98 & 0.99 & 0.99 & & 0.94 & 0.99 & 0.97 \\
\hline
\end{tabular}

following factors: (a) measurement errors; (b) use of overparameterized model structures; (c) inappropriate representation of the temporal and spatial variability of model inputs; (d) poor identification of initial and boundary conditions; (e) non-informativeness of calibration data with regard to the entire system regime; (f) use of statistically inconsistent fitting criteria; $(\mathrm{g})$ inconsistent assumption of parameters constant in time whilst the environment is changing $[10,11,17,19,43,55]$. Therefore, recycling these errors and uncertainties in the model could have resulted in the poor predictive model capacity against independent control period (validation) as observed in this case.

Figure 8 shows hydrographs for both the calibration and validation periods for gauge station Chache. In the 
Calibration

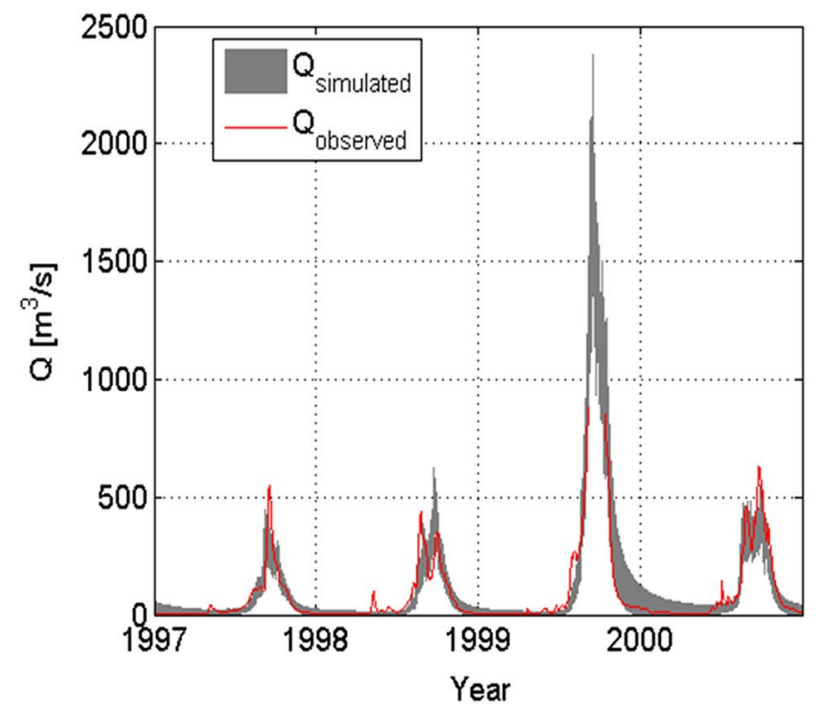

Validation

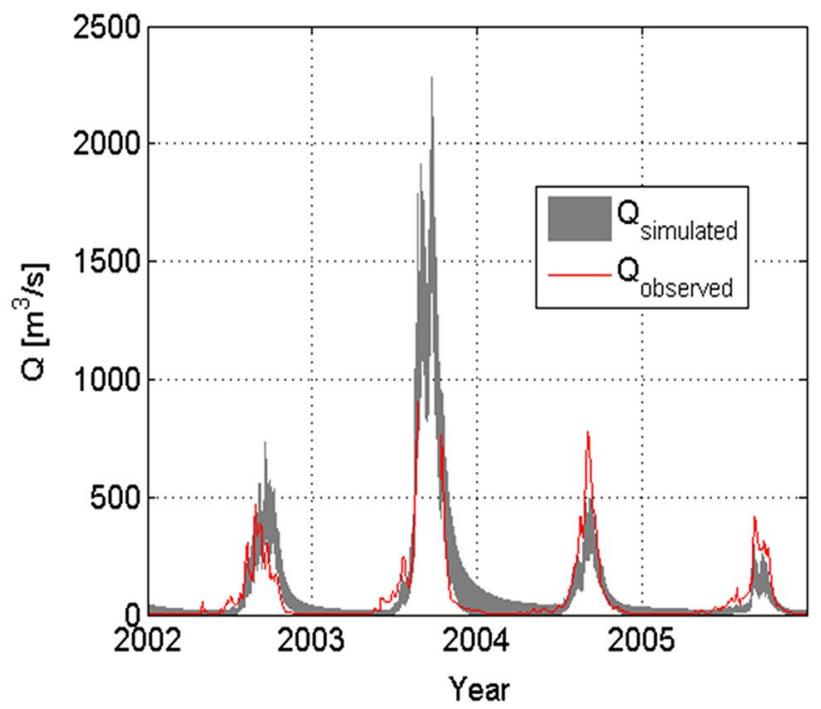

Fig. 8 Hydrographs for sub-catchment Chache showing both the calibration and validation periods

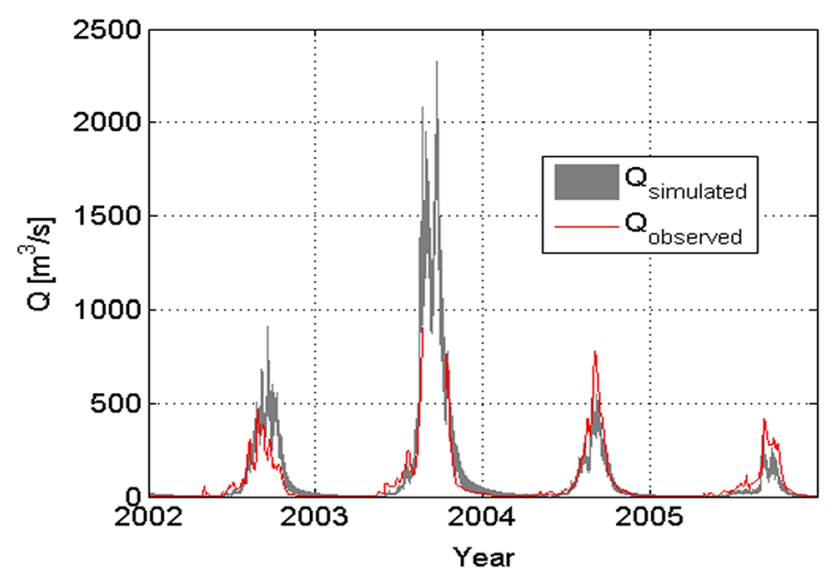

Fig. 9 Hydrograph for calibration of the model for gauge Chache using (NS +3LogNS) as the objective function

hydrograph, it could be seen that the model overestimates the peaks in both the calibration and validation periods which could be as a result of error(s) in either the model set-up or the observed data or maybe due to the few gaps in the observed discharge. This phenomenon was also reported by Götzinger [20]. It is observed in the hydrographs in Figs. 8 and 9 that the model is slightly weak in simulating the low flows. The model performs rather slightly better when the sub-catchment size is increased as in the case of sub-catchment Chache (Fig. 8). In the Chache sub-catchment, mean NS values are 0.80 and 0.60 for calibration and validation respectively. The estimation of the peaks is better in this sub-catchment. There is not much difference in either using the Log NS or NS-Bias as the objective function for calibrating and assessing model performance. However, there is an improvement in the model performance for subcatchment Chache when a bigger weight is given to the LogNS (i.e. using (NS + $3 \log N S$ ) $/ 4$ as the objective function) with a mean value of 0.79 for calibration and 0.64 for validation (Table 3 ). This objective function is then used to calibrate and assess the performance of the model as well as focusing on the low flows.

However, the performance was not better when the Log NS or the combination of the two as the objective function was used. Moreover, using NS-Bias as the objective function did not have a significant effect on the performance of the model for both subcatchments and periods (Tables 2 , 3). There was a slight improvement in the performance and better simulation of the low flows when a higher weight was given to the LogNS during its combination with NS (i.e. (NS + 3LogNS)/4) for the simulation periods for subcatchment Chache (Fig. 9).

\subsection{Calibrating on daily temporal scale and checking performance on different scales}

To determine how robust the model is and how well it reacts to rainfall input signals, it was calibrated on the daily temporal scale and performances checked on the monthly and residuals or net discharge (obtained by subtracting the annual cycle from the daily data). Table 4 and Figs. 10, 11 and 12 show the results for this case. In this case, (NS + 3LogNS)/4 was used as the objective function during the optimisation. From the results, it could be observed that the model performed better during calibration than the validation period. The annual cycle was deducted from 
Table 4 Calibration and validation results for Chache by calibrating on daily scale and checking performances on other temporal scales with (NS +3LogNS) as the objective function

Fig. 10 Hydrograph showing the model performance on the daily residuals after calibration on the daily scale
Fig. 11 Hydrograph showing the model performance on the monthly simulations after calibration on the daily scale

\begin{tabular}{llllllll}
\hline Temporal scales & \multicolumn{3}{l}{ Calibration (1996-2000) } & & \multicolumn{3}{l}{ Validation (2001-2005) } \\
\cline { 2 - 3 } & Min & Max & Mean & & Min & Max & Mean \\
\hline Daily & 0.75 & 0.82 & 0.79 & & 0.6 & 0.68 & 0.64 \\
Daily Residual & 0.17 & 0.52 & 0.35 & & 0.11 & 0.4 & 0.26 \\
Monthly & 0.86 & 0.87 & 0.87 & & 0.69 & 0.7 & 0.7 \\
Monthly Residual & 0.61 & 0.65 & 0.63 & & 0.48 & 0.5 & 0.49 \\
\hline
\end{tabular}
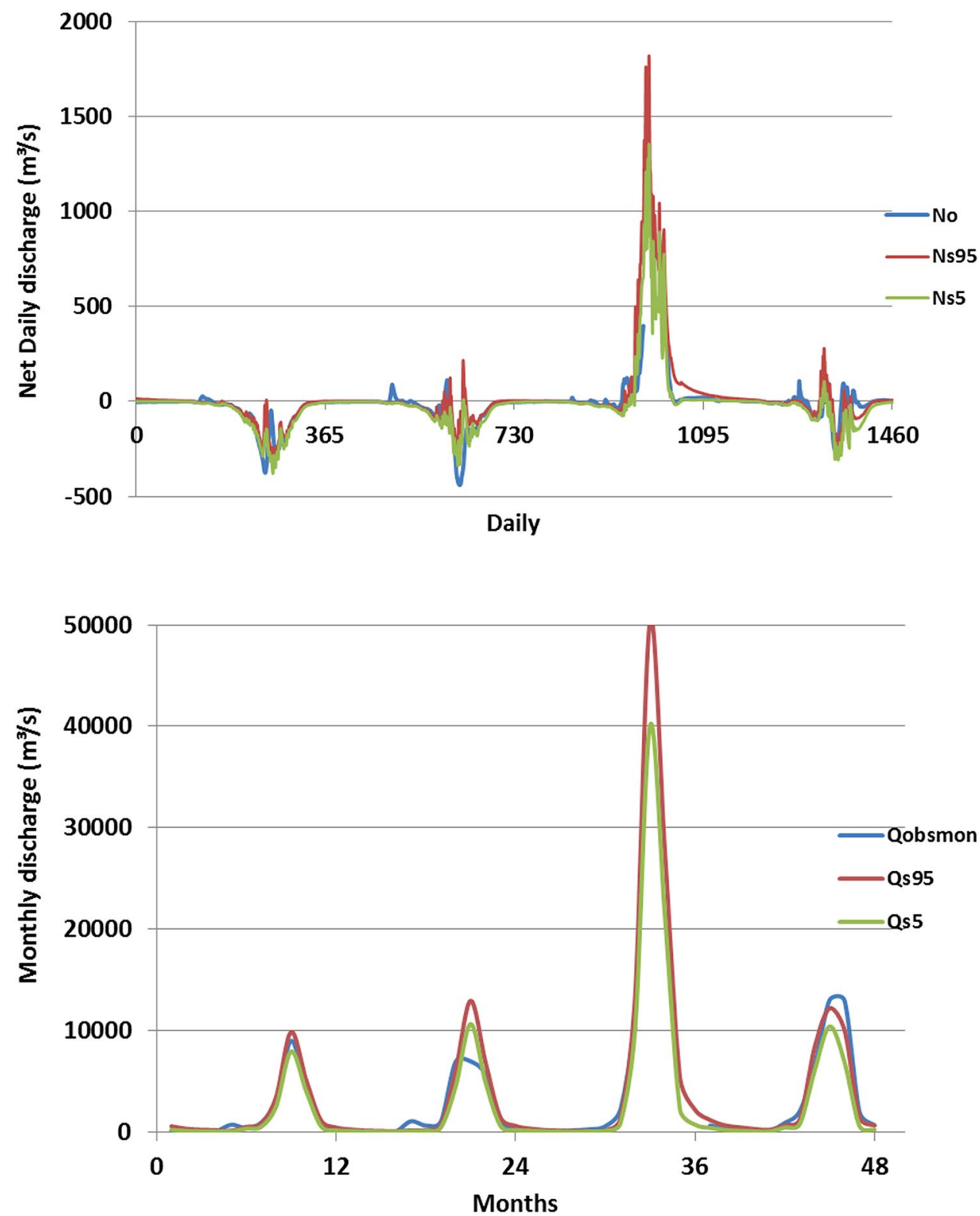

the daily and monthly data to assess how the model performed when seasonality was removed. This model can serve as a benchmark similar to what Schaefli \& Gupta [45] reported in their studies. Using the net discharge or residuals as the benchmark, the model performance doubled in the daily time scales as compared with the daily residuals, as well as for the monthly time scales. The model performed quite well when the annual cycle was deducted from the data (i.e. residuals or the net discharge) which signifies how the model reacts to rainfall input signals. The performance was improved when it was checked on the monthly scale and the monthly residuals. Hence, the 
Fig. 12 Hydrograph showing the model performance on the monthly residuals after calibration on the daily scale

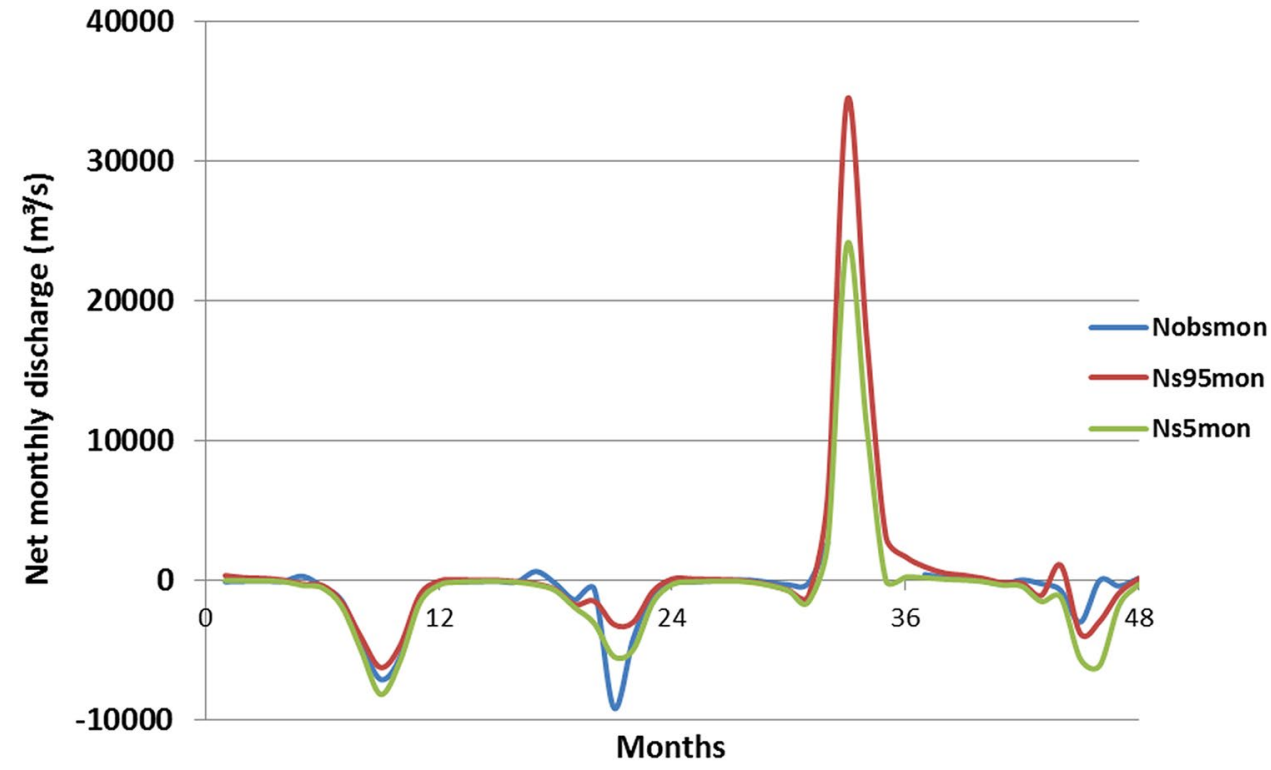

model performs well on different temporal scales and able to capture both deficit and surplus water volumes relative to the annual cycle.

\subsection{Calibration on different temporal scales}

In this case, calibration and validation were done using different temporal scales (i.e. daily, monthly, daily and monthly residuals) to determine how well the model performs on different scales. The results for this could be seen in Table 5 and Figs. 13 and 14. Calibration was performed using both (NS + 3LogNS)/4 and NS as objective functions (Table 5). The model performs very well during the daily and monthly calibrations but loses some efficiency during the calibration on daily and monthly residuals. This observation was also emphasised in the research of Schaefli \&
Gupta [45]. Calibrating on monthly scale shows very high performance which makes the model suitable for water resource management. These performances exceed the daily calibration and checking performance on different scales which was earlier discussed. Calibrating on monthly scale could reach a mean NS performance as high as 0.96 (Table 5).

\subsection{Swapping of data for calibration and validation}

The data used for calibration was swapped with that which was used for validation to check how the model performs under different conditions and times. Table 6 and Fig. 15 show the results for the gauge station Chache when calibration was done on the daily and monthly scales. It is striking to know that the model performed creditably

Table 5 Model performance on gauge Chache for calibration on different temporal scales using (NS + 3LogNS)/4 and NS as the performance measurement functions

\begin{tabular}{|c|c|c|c|}
\hline \multirow[t]{2}{*}{ Performance measure: (NS + 3LogNS)/4 } & \multicolumn{3}{|c|}{ Calibration (1996-2000) } \\
\hline & Min & Max & Mean \\
\hline Daily & 0.75 & 0.82 & 0.79 \\
\hline Monthly & 0.87 & 0.93 & 0.9 \\
\hline Daily Residual & $\mathrm{N} / \mathrm{A}$ & N/A & N/A \\
\hline Monthly Residual & $\mathrm{N} / \mathrm{A}$ & N/A & N/A \\
\hline \multirow[t]{2}{*}{ Performance measure: NS } & \multicolumn{3}{|c|}{ Calibration (2001-2005) } \\
\hline & Min & Max & Mean \\
\hline Daily & 0.68 & 0.88 & 0.78 \\
\hline Monthly & 0.92 & 0.96 & 0.94 \\
\hline Daily Residual & 0.48 & 0.53 & 0.51 \\
\hline Monthly Residual & 0.32 & 0.51 & 0.42 \\
\hline
\end{tabular}




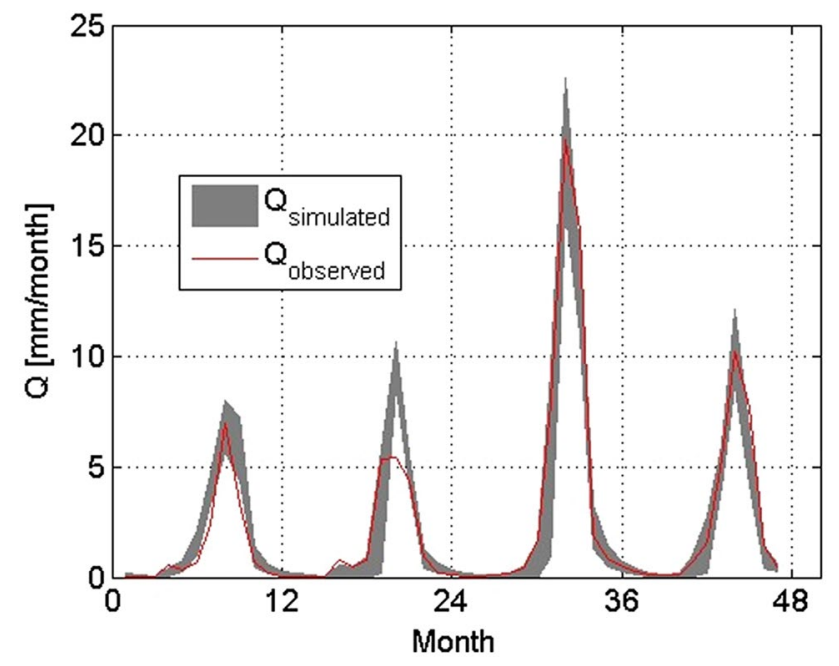

Fig. 13 Hydrograph showing the model performance for gauge Chache when calibration was done on monthly scale

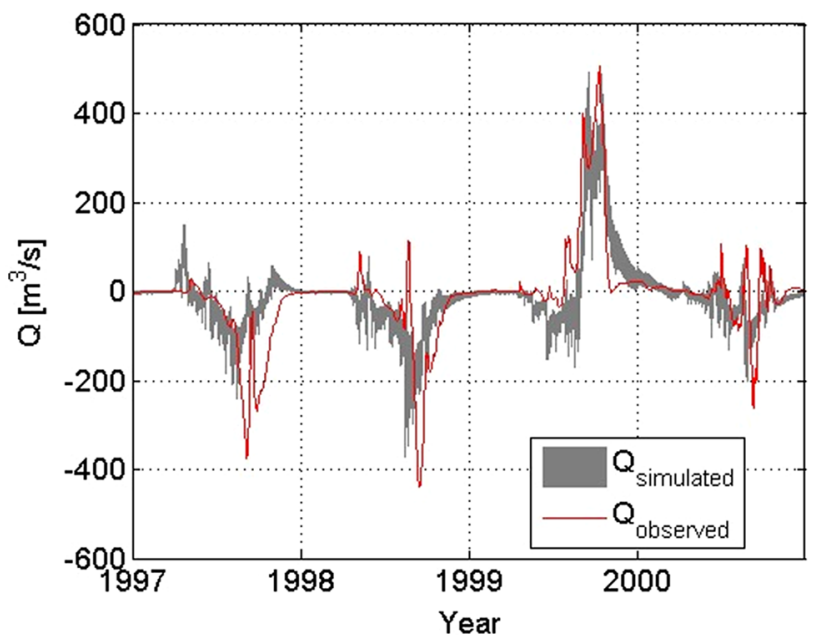

Fig. 14 Hydrograph showing the model performance for gauge Chache when calibration was done on daily residuals well during both scenarios for both calibration and validation for the daily and monthly scales. Almost the same performance (NS $=0.78$ ) was realized for both swapped calibration years (i.e. 1996-2000 and 2001-2005). This means that it doesn't matter which 5-year period was used to calibrate the model since the same performance results are obtained. For validation, the 5 -year period (1996-2000) shows improved results than the other period (2001-2005). Also, in that year period the validation results were unexpectedly slightly higher than the calibration results. This is because in general, calibration results are expected to be better than validation results.

The results of this study support the general findings of Niel et al. [37], that there is parameter stability when applying lumped hydrological model for some West and Central African catchments. Overall, the performance of the model and the results are not different from the work of previous researchers (e.g. [1, 20, 26, 40, 47, 54].

\subsection{Calibrating on dry and validating on wet and vice versa}

In trying to investigate the transferability of the model to different years and catchment and to also know how it reacts to rainfall signals, the split sampling was done. In the split sampling, the data was split into two parts (namely the wet and dry years). A 3-year period which was termed "dry" and another 3-year period termed "wet" was used for both the calibration and validation with the first year being a warm-up period for the model. Calibration of the model was done for wet years (1994, 1996 and 1999 for gauge Lawra) while validation was done for dry years (1993, 1995 and 1998) and vice and versa. For gauge Chache, the wet years were 1999, 2003 and 2004 and the dry years were 1997, 1998 and 2005. The results of this could be seen in Tables 7 and 8 and Figs. 16 and 17. The results of the split sampling emphasizes that the

Table 6 Model performance for gauge Chache for a swapped data for calibration and validation period

\begin{tabular}{|c|c|c|c|c|c|c|}
\hline \multicolumn{7}{|l|}{ CASE I: } \\
\hline \multirow{2}{*}{$\begin{array}{l}\text { Perf. measure: } \\
\text { (NS + 3LogNS)/4 }\end{array}$} & \multicolumn{3}{|c|}{ Calibration (1996-2000) } & \multicolumn{3}{|c|}{ Validation (2001-2005) } \\
\hline & Min & Max & Mean & Min & Max & Mean \\
\hline Daily & 0.75 & 0.82 & 0.79 & 0.6 & 0.68 & 0.64 \\
\hline Monthly & 0.87 & 0.93 & 0.9 & 0.63 & 0.88 & 0.76 \\
\hline \multicolumn{7}{|l|}{ CASE II: } \\
\hline \multirow{2}{*}{$\begin{array}{l}\text { Perf. measure: } \\
\text { (NS + 3LogNS)/4 }\end{array}$} & \multicolumn{3}{|c|}{ Calibration (2001-2005) } & \multicolumn{3}{|c|}{ Validation (1996-2000) } \\
\hline & Min & Max & Mean & Min & Max & Mean \\
\hline Daily & 0.74 & 0.82 & 0.78 & 0.71 & 0.88 & 0.8 \\
\hline Monthly & 0.61 & 0.89 & 0.75 & 0.73 & 0.93 & 0.83 \\
\hline
\end{tabular}



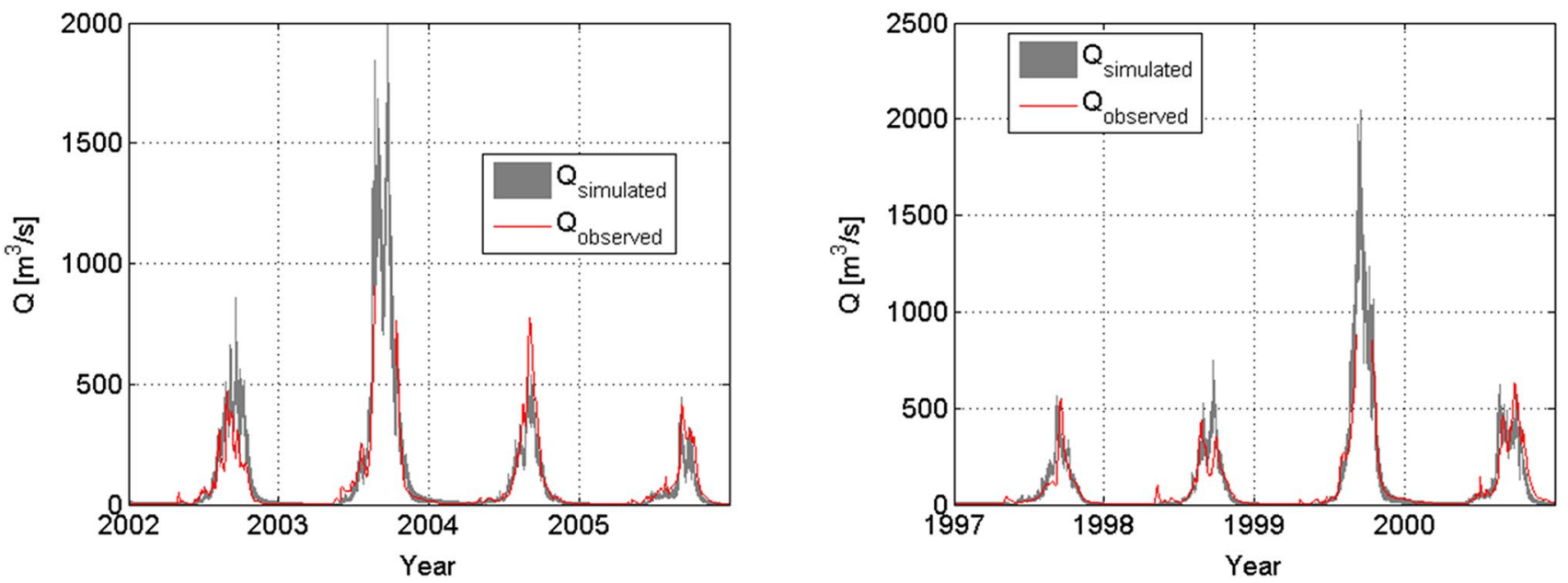

Fig. 15 Hydrograph showing model performance for gauge Chache on daily temporal scale for swapped calibration and validation data

Table 7 Model performance for Lawra on split sampling (calibration and validation)

\begin{tabular}{|c|c|c|c|c|c|c|}
\hline \multicolumn{4}{|l|}{ Calibration (dry) } & \multicolumn{3}{|c|}{ Validation (wet) } \\
\hline Perf. measure & Min & Max & Mean & Min & Max & Mean \\
\hline NS & 0.61 & 0.78 & 0.69 & 0.54 & 0.65 & 0.57 \\
\hline Correlation & 0.82 & 0.94 & 0.85 & 0.74 & 0.81 & 0.76 \\
\hline \multicolumn{4}{|c|}{ Calibration (wet) } & \multicolumn{3}{|c|}{ Validation (dry) } \\
\hline Perf. measure & Min & Max & Mean & Min & Max & Mean \\
\hline NS & 0.71 & 0.85 & 0.76 & 0.28 & 0.59 & 0.49 \\
\hline Correlation & 0.85 & 0.94 & 0.88 & 0.62 & 0.69 & 0.68 \\
\hline
\end{tabular}

Table 8 Model performance for Chache on split sampling (calibration and validation)

\begin{tabular}{|c|c|c|c|c|c|c|}
\hline \multicolumn{4}{|l|}{ Calibration (dry) } & \multicolumn{3}{|c|}{ Validation (wet) } \\
\hline Perf. measure & Min & Max & Mean & Min & Max & Mean \\
\hline NS & 0.74 & 0.87 & 0.79 & 0.52 & 0.81 & 0.7 \\
\hline Correlation & 0.88 & 0.94 & 0.9 & 0.83 & 0.95 & 0.89 \\
\hline \multicolumn{4}{|l|}{ Calibration (wet) } & \multicolumn{3}{|c|}{ Validation (dry) } \\
\hline Perf. measure & Min & $\operatorname{Max}$ & Mean & Min & Max & Mean \\
\hline NS & 0.69 & 0.91 & 0.82 & 0.63 & 0.81 & 0.67 \\
\hline Correlation & 0.85 & 0.97 & 0.93 & 0.86 & 0.92 & 0.89 \\
\hline
\end{tabular}

model reacts well to rainfall input signals and it performs better in the wet conditions than the dry. The two subcatchments showed very encouraging results especially for the wet calibrations and validations. But, in both the dry calibration and wet validation, the model was slightly late and also overestimated the peak discharge which is in contrast to the research work of Ricard et al. [41].

\section{Conclusions}

The robustness and performance of the HBV rainfallrunoff model was assessed by using various calibration and validation techniques (i.e. modeling in different sub-catchments, calibrating on daily temporal scale and checking performance on different scales, calibrating on 



Fig. 16 Hydrographs of split sampling for sub-catchment Lawra showing both the calibration and validation periods

different temporal scales, swapping of data for calibration and validation and calibrating on dry and validating on wet and vice versa ("split sampling")). Two different subcatchments (Lawra and Chache) were used for the studies.

In assessing how well the model performs, different objective functions including Nash-Sutcliffe (NS), the logarithmic of the Nash-Sutcliffe (LogNS), the Nash-Sutcliffe with a bias constraint (NS-Bias) and correlation were used. The robust parameter estimation (ROPE) was used to generate and calibrate 10,000 best parameter sets in a computer framework with initially set model parameter ranges.

The model performed well for both subcatchments with an average NS of 0.75 and 0.57 for calibration and validation respectively for subcatchment Lawra. However, there was an improvement in the model performance, when a bigger weight was given to the LogNS (i.e. using (NS + 3LogNS)/4 as the objective function). This is an indication of better simulation of the low-flows. Better simulation of the low flows is very important in this study because one of the key objectives of the model is for management of the water resources at low flow (drought) conditions. In all, results showed that the model was stable and reacted well to precipitation signals. The annual discharge cycle was subtracted from both the observed and simulated data and then the model performance was determined. The model performed well on different temporal scales and was able to capture both deficit and surplus water volumes relative to the annual cycle. The weak point of the model is the overestimation of the peaks at certain times.

The dataset used for calibration was swapped with that which was used for validation to check how the model performed under different conditions and times. It was striking to know that the model performed creditably well during both scenarios for both calibration and validation for the daily and monthly scales. The results of split sampling, where the rainfall input data is split into "wet" and "dry" periods further emphasized that the model reacted well to rainfall input signals and performed better in the wet conditions than the dry.

This study revealed that the HBV model could be used to undertake water resources management in the subregion. The main usage of water in the region is for hydropower and farming, so knowing or predicting the daily 

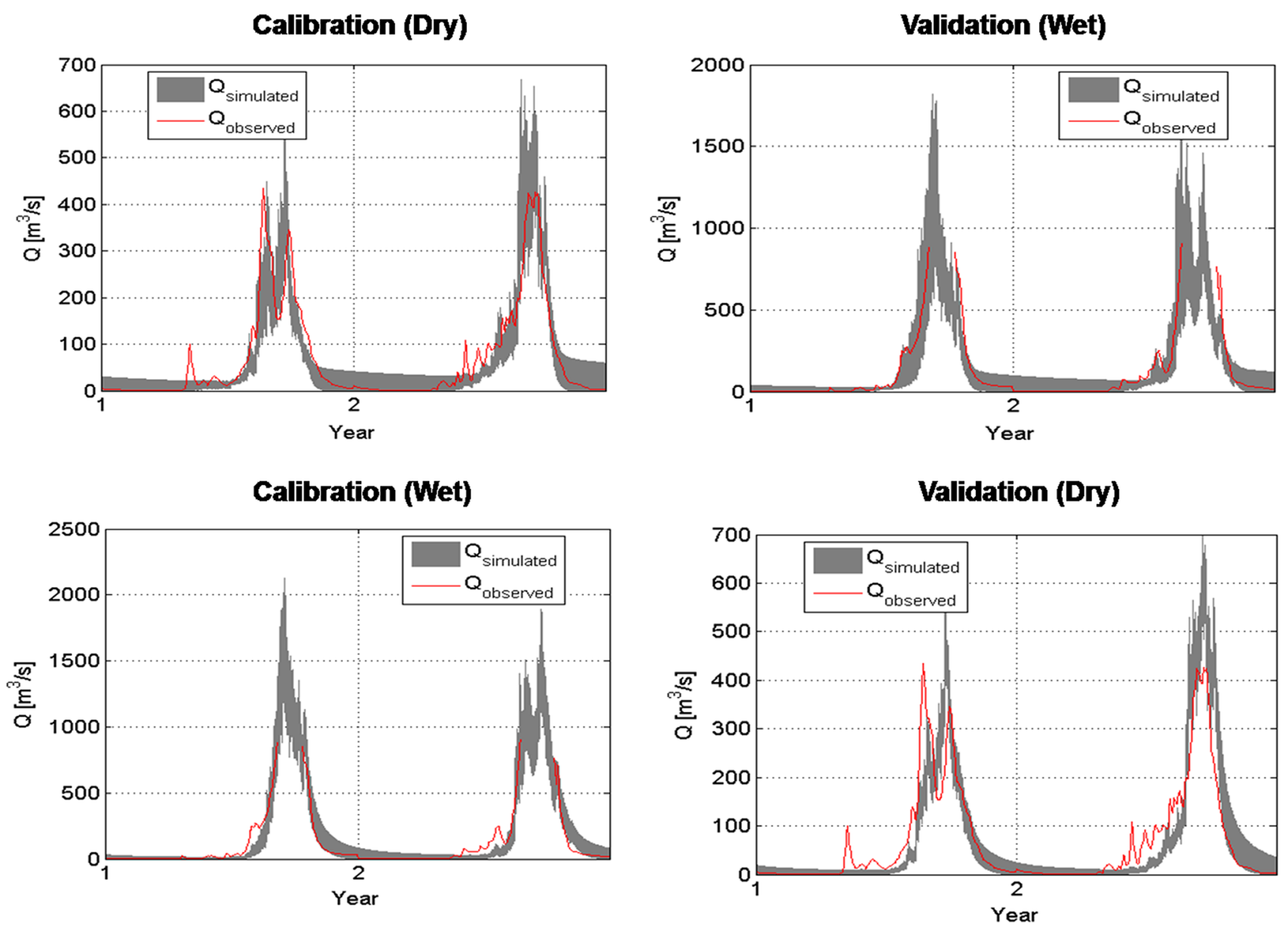

Fig. 17 Hydrographs of split sampling for sub-catchment Chache showing both the calibration and validation periods

or monthly volumes of river flow would be beneficial to the farmers and the hydropower authorities. The model could obviously help in the simulation of water levels of the dams for the hydropower authorities.

Moreover, the Black Volta is a transboundary basin and therefore a good water resource management with a hydrological model would be beneficial to a lot of countries in the sub-region. The misunderstandings that sometimes occur among the various countries as a result of water resources management could be minimised or eliminated as a result of the application of hydrological models such as the one in our study to simulate river flow for efficient management of the water resources.

The results of this study confirm what Götzinger [20] reported in his study that the total simulated discharge matches the scale and variability of the observations sufficiently well for water resources management planning and that the general seasonal behavior but not all observed flood peaks could be reproduced.

Overall, the study revealed that the lumped HBV model could be well applied in a data scarce environment and a semi-arid to humid climate such as Western Africa to give favourable and good results. This study could be used in a further study to assess the effects of climate change on the water resources of the sub-region.

Acknowledgements Many thanks to the Meteorological services department of both Ghana and Burkina Faso for providing us with the meteorological data for this study. Also, special thanks to the Hydrological Services Department in Ghana for the hydrological data. We further extend our sincere gratitude to Prof. Dr. Harald Kunstmann of the University of Augsburg and to Antonio Rogmann of WASCAL for granting us the access to the GLOWA VOLTA geoportal.

\section{Compliance with ethical standards}

Conflict of interest On behalf of all authors, the corresponding author states that there is no conflict of interest.

\section{References}

1. Amisigo BA, Van de Giesen N, Rogers C, Andah WEl, Friesen $J$ (2008) Monthly streamflow prediction in the volta basin of 
west africa: A siso narmax polynomial modelling. Phys Chem Earth Parts A/B/C 33(1):141-150

2. Amisigo BA, Van De Giesen NC (2005) Using a spatio-temporal dynamic state-space model with the EM algorithm to patch gaps in daily riverflow series. Hydrol Earth Syst Sci Dis 9(3):209-224

3. Andersen J, Refsgaard JC, Karsten HJ (2001) Distributed hydrological modelling of the senegal river basin model construction and validation. J Hydrol 247(3):200-214

4. Bárdossy A, Pegram GG (2016) Space-time conditional disaggregation of precipitation at high resolution via simulation. Water Resour Res 52(2):920-937

5. Bardossy A, Singh SK (2008) Robust estimation of hydrological model parameters. Hydrol Earth Syst Sci 12(6):1273-1283

6. Bárdossy A, Huang Y, Wagener T (2016) Simultaneous calibration of hydrological models in geographical space

7. Bergstrom S (2006) Experience from applications of the HBV hydrological model from the perspective of prediction in ungauged basins. IAHS 307:97

8. Bergström S (1995) The HBV model in: Computer models of watershed hydrology. Water Resources Publications, Littleton, Colorado, USA

9. Bergström S, Forsman A (1973) Development of a conceptual deterministic rainfall-runoff model. Nord Hydrol 4:174-190

10. Beven KJ, Binley AM (1992) The future of distributed models: model calibration and uncertainty prediction. Hydrol Processes 6(3):279-298

11. Beven KJ, Smith PJ, Freer J (2008) So just why would a modeller choose to be incoherent? J Hydrol 354:15-32

12. Beven KJ (2011) Rainfall-runoff modelling: the primer. Wiley, London

13. Devia GK, Ganasri BP, Dwarakish GS (2015) A review on hydrological models. Aquat Proc 4:1001-1007

14. Dembélé $M$, Oriani $F$, Tumbulto J, Mariéthoz G, Schaefli B (2018) Gap-filling of daily streamflow time series using Direct Sampling in various hydroclimatic settings. J Hydrol

15. Dezetter A, Girard S, Paturel JE, Mahe G, Ardoin-Bardin S, Servat $E$ (2008) Simulation of runoff in west africa: is there a single data-model combination that produces the best simulation results? J Hydrol 354(1):203-212

16. Ding J, Wallner M, Müller H, Haberlandt U (2016) Estimation of instantaneous peak flows from maximum mean daily flows using the HBV hydrological model. Hydrol Process 30(9):1431-1448

17. Efstratiadis A, Koutsoyiannis D (2008) Fitting hydrological models on multiple responses using the multiobjective evolutionary annealing-simplex approach. In: Practical hydroinformatics: computational intelligence and technological developments in water applications. Springer Water Science and Technology Library, vol. 68, Springer-Verlag, Berlin, Germany, pp 259-273

18. Efstratiadis A, Koutsoyiannis D (2010) One decade of multiobjective calibration approaches in hydrological modelling: a review. Hydrol Sci J 55:58-78

19. Engeland $K, X u C Y$, Gottschalk L (2005) Assessing uncertainties in a conceptual water balance model using Bayesian methodology. Hydrol Sci J 50(1):45-63

20. Götzinger J (2007) Distributed conceptual hydrological modelling-simulation of climate, land use change impact and uncertainty analysis. Thesis (PhD). University of Stuttgart, Germany

21. Grillakis MG, Tsanis IK, Koutroulis AG (2010) Application of the HBV hydrological model in a flash flood case in Slovenia. Nat Hazards Earth Syst Sci 10(12):2713-2725

22. Gupta HV et al (2009) Decomposition of the mean squared error and nse performance criteria: implications for improving hydrological modelling. J Hydrol 377(1):80-91
23. Harlin J (1991) Development of a process oriented calibration scheme for the HBV hydrological model. Hydrol Res 22(1):15-36

24. Hundecha Y, Bardossy A (2004) Modeling of the effect of land use changes on the runoff generation of a river basin through parameter regionalization of a watershed model. J Hydrol 292(1):281-295

25. Ibrahim B, Karambiri H, Polcher J, Yacouba H, Ribstein P (2014) Changes in rainfall regime over Burkina Faso under the climate change conditions simulated by 5 regional climate models. Clim Dyn 42(5-6):1363-1381

26. Jung G (2006) Regional climate change and the impact on hydrology in the Volta basin of west africa. Thesis (PhD). University of Augsburg, Germany

27. Jung $G$, Kunstmann $H$ (2007) High-resolution regional climate modeling for the volta region of west africa. J Geophys Res Atmos 112(D23)

28. Jung G, Wagner S, Kunstmann H (2012) Joint climatehydrology modeling: an impact study for the data-sparse environment of the Volta basin in west Africa. Hydrol Res 43(3):231-248

29. Kasei RA (2010) Ecol Dev Ser 69:2010

30. Kunstmann H, Jung G (2005) Impact of regional climate change on water availability in the volta basin of west africa. Regional hydrological impacts of climate variability and change. In: Proceedings of symposium S6 for the seventh IAHS scientific assembly. Foz de Iguacu, Brazil

31. Laprise R, Hernandez-Dıaz L, Tete K, Sushama L, Separovic L, Martynov A, Winger K, Valin M (2013) Climate projections over cordex africa domain using the fifth-generation canadian regional climate model (crcm5). Clim Dyn 41(11-12):3219-3246

32. Lindström G et al (1997) Development and test of the distributed hbv-96 hydrological model. J Hydrol 201(1):272-288

33. Liu Y, Yao X (1999) Ensemble learning via negative correlation. Neural Netw 12(10):1399-1404

34. McCartney M, Forkuor G, Sood A, Amisigo B, Hattermann F, Muthuwatta $L$ (2012) The water resource implications of changing climate in the Volta River Basin, volume 146. IWMI

35. Mul M, Obuobie E, Appoh R, Kankam-Yeboah K, Bekoe-Obeng E, Amisigo B, McCartney M (2015) Water resources assessment of the Volta River Basin, Vol. 166. International Water Management Institute (IWMI)

36. Nash JE, Sutcliffe JV (1970) River flow forecasting through conceptual models part I-a discussion of principles. J Hydrol 10(3):282-290

37. Niel H, Paturel JE, Servat E (2003) Study of parameter stability of a lumped hydrologic model in a context of climatic variability. J Hydrol 278(1):213-230

38. Paeth $\mathrm{H}$, Hall NMJ, Gaertner MA, Alonso MD, Polcher SM, Ruti PM, Fink $\mathrm{H}$ et al (2011) Progress in regional downscaling of west african precipitation. Atmos Sci Lett 12(1):75-82

39. Patricola CM, Cook KH (2011) Sub-saharan northern african climate at the end of the twenty first century: forcing factors and climate change processes. Clim Dyn 37(5-6):1165-1188

40. Paturel JE, Ouedraogo M, Mahe G, Servat E, Dezetter A, Ardoin $S$ (2003) The influence of distributed input data on the hydrological modelling of monthly river flow regimes in west africa. Hydrol Sci J 48(6):881-890

41. Ricard S, Bourdillon R, Roussel D, Turcotte R (2013) Global calibration of distributed hydrological models for large scale applications. J Hydrol Eng 18:719-721

42. Rodriguez Suarez JA, Diaz-Fierros F, Perez R, Soto B (2014) Assessing the influence of afforestation with Eucalyptus globulus on hydrological response from a small catchment in northwestern Spain using the HBV hydrological model. Hydrol Process 28(22):5561-5572 
43. Rosbjerg D, Madsen $\mathrm{H}$ (2005) Concepts of hydrologic modeling. In: Anderson MG (ed) Encyclopedia of hydrological sciences. Chap. 10. Wiley, Chichester

44. Rousseeuw PJ, Struyf A (1998) Computing location depth and regression depth in higher dimensions. Stat Comput 8(3):193-203

45. Schaefli B, Gupta HV (2007) Do Nash values have value? Hydrol Process Int J 21(15):2075-2080

46. Shahin M (2006) Hydrology and water resources of Africa, vol 41. Springer, Berlin

47. Shaibu S, Odai SN, Adjei KA, Osei EM, Annor FO (2012) Simulation of runoff for the black volta basin using satellite observation data. Int J River Basin Manag 10(3):245-254

48. Sidibe M, Dieppois B, Mahé G, Paturel JE, Amoussou E, Anifowose B, Lawler D (2018) Trend and variability in a new, reconstructed streamflow dataset for West and Central Africa, and climatic interactions, 1950-2005. J Hydrol 561:478-493

49. Singh SK, Bardossy A (2012) Calibration of hydrological models on hydrologically unusual events. Adv Water Resour 38:81-91

50. Speth P, Christoph M, Diekkruger B (2010) Impacts of global change on the hydrological cycle in west and northwest Africa. Springer, Berlin

51. Taylor JC, van de Giesen N, Steenhuis TS (2006) West Africa: volta discharge data quality assessment and use. JAWRA J Am Water Resour Assoc 42(4):1113-1126

52. Tukey JW (1975) Mathematics and the picturing of data. In: Proceedings of the international congress of mathematicians, Vancouver, 1975, vol 2, pp 523-531
53. Viney $\mathrm{N}$ et al (2009) The usefulness of bias constraints in model calibration for regionalisation to ungauged catchments. In: 18th World IMACS Congress and MODSIM09 International Congress on Modelling and Simulation. Modelling and Simulation Society of Australia and New Zealand and International Association for Mathematics and Computers in Simulation: Cairns, 13-17

54. Wagner $S$ (2008) Water balance in a poorly gauged basin in West Africa using atmospheric modelling and remote sensing information. Thesis (PhD). University of Stuttgart, Germany

55. Wagener T, Gupta HV (2005) Model identification for hydrological forecasting under uncertainty. Stoch Environ Res Risk Assess 19:378-387

56. Williams TO, Mul M, Biney CA, Smakhtin V (eds) (2016) The Volta River basin: Water for food, economic growth and environment. Routledge

57. Zhang X, Lindström G (1997) Development of an automatic calibration scheme for the HBV hydrological model. Hydrol Process 11(12):1671-1682

58. Zuo Y, Serfling R (2000) Structural properties and convergence results for contours of sample statistical depth functions. Ann Stat 483-499

Publisher's Note Springer Nature remains neutral with regard to jurisdictional claims in published maps and institutional affiliations. 